\title{
Xanthine Oxidase Inhibitory Effect of Alternanthera Sessilis
}

\author{
Harita Ravikumar ${ }^{1}$, Kavitha $S^{2}$, V. Vishnupriya ${ }^{3}$ and Gayathri.R ${ }^{4}$ \\ ${ }^{1}$ Saveetha Dental College and Hospitals, Saveetha Institute of Medical and \\ Technical Science(SIMATS),Saveetha University, Chennai-600077, India \\ ${ }^{2}$ Lecturer Department of Biochemistry Saveetha Dental College and Hospitals, \\ Saveetha Institute of Medical and Technical Sciences (SIMATS), Saveetha University, \\ Chennai-600077, India \\ ${ }^{3}$ Professor Department of Biochemistry, Saveetha Dental College and Hospitals. \\ Saveetha Institute of Medical and Technical Sciences (SIMATS), Saveetha University, \\ Chennai-600077, India \\ ${ }^{4}$ Professor Department of Biochemistry, Saveetha Dental College and Hospitals. \\ Saveetha Institute of Medical and Technical Sciences (SIMATS), Saveetha University, \\ Chennai-600077, India
}

\section{ABSTRACT}

Alternanthera sessilis is one of the useful medicinal plants which is also used in diet by many people of Asia and other regions. This plant has shown many therapeutic uses such as anti- inflammatory, anti-diarrhoeal, antimicrobial, antioxidant and also hepatoprotective activities. Xanthine oxidase is a flavoprotein enzyme whose high activity will lead to excessive production of uric acid which will then get accumulated in muscles and joints leading to a diseased condition called gout. The present study was aimed to assess the xanthine oxidase inhibitory effect on Alternanthera sessilis leaf extract and to screen the phytochemical constituents in it. Ethanolic extract of Alternanthera sessilis leaves was used for the study. Phytochemical screening and the inhibitory activity of this plant extract were analysed. The result showed the potent xanthine oxidase inhibitory effect of the plant in a concentration dependent manner. The phytochemical screening also revealed that the extract is rich in alkaloids, terpenoids, flavonoids, phlobatannins and carbohydrates. The study showed that the ethanolic extract of Alternanthera sessilis showed potent in vitro xanthine oxidase inhibitory activity and is rich in the presence of phytochemical constituents. Further detailed studies have to be done to elucidate the underlying mechanism of its activity and to develop it as a drug for the treatment for gout.

KEY WORDS: ALTERNANTHERA SESSILIS; XANTHINE OXIDASE; PHYTOCHEMICAL SCREENING; GOUT.

\section{ARTICLE INFORMATION}

*Corresponding Author: kavithas.sdc@saveetha.com

Received 5th Aug 2020 Accepted after revision 24th Sep 2020

Print ISSN: 0974-6455 Online ISSN: 2321-4007 CODEN: BBRCBA

Thomson Reuters ISI Web of Science Clarivate Analytics USA and Crossref Indexed Journal

$$
\begin{aligned}
& \text { Clarivate } \\
& \text { Analytics }
\end{aligned}
$$




\section{INTRODUCTION}

Xanthine oxidase is a flavoprotein enzyme which helps in catalyzing purine which undergoes oxidative hydroxylation reaction at the molybdenum center (Borges, Fernandes and Roleira, 2002). In human tissues, xanthine oxidase is predominantly present in the liver and small intestine (Elion, Kovensky and Hitchings, 1966). Inhibition of xanthine oxidase can cure various diseases most importantly gout. It is the enzyme which converts hypoxanthine to xanthine and then to Uric acid (Morgan, 1926). Gout is the most widespread form of inflammatory arthritis which is associated with affecting the life of people. Increase in uric acid level in serum or their accumulation in joints is the common development of gout (Ferraz Filha et al., 2006). The initial symptoms of gout takes place all of a sudden and rapid which occurs especially during the night time. First affected part of the body is the big toe where the uric acid is accumulated which becomes red and swollen, the veins dilate and the skin appears bruised (Roddy and Doherty, 2010).

Allopurinol is a well-known inhibitor of xanthine oxidase, and is used for the testament of gout. The metabolic deposition of allopurinol was determined in many living beings such as dogs, mites and human beings. Allopurinol, a substrate which also acts as an inhibitor of xanthine oxidase, converted to alloxanthine, a metabolite. Alloxanthine accumulation with allopurinol during the prolonged therapy contributes in controlling hyperuricemia. Allopurinol is a synthetic drug and it has many side effects such as fever, sore throat etc. and hence many efforts are being made to find natural remedies for out and other hyperuricemic diseases (Busso and So, 2010).

Alternanthera sessilis (A. sessilis) is an aquatic plant which can be observed or seen in marshy areas and wetlands especially in Bangladesh. This plant is used as a medicine in folklore. They were especially used to treat wounds and pain. In different parts of India it is used in curing different diseases. They used to treat ulcers, treat gonorrhoea, low sperm count, fevers, dyspepsia, liver and spleen diseases. In Tamil Nadu, it is used in the treatment of headache,

hepatitis and asthma (Hossain et al., 2014)

Taxonomical classification:(Taxon, Red and List, 2015)

Kingdom: Plantae

Phylum:Angiosperms

Class: Eudicots

Order: Caryophyllales

Family: Amaranthaceae

Sub-family: Gomphrenoideae

Genus: Alternanthera

Species: sessilis

It is a perennial herb with prostrate stems, which is ascending and roots often have nodes. Flowers in sessile spikes, bracts and bracteoles. They are highly branched and their height differs with the humidity level. In flooded areas it is seen floating with several meters in height (Grubben and Denton, 2004). Alternanthera sessilis has anti-viral, anti-fungal, anti-microbial, antiinflammatory and much more properties (Kumar et al., 2014). This plant contains 2, 4- methylenecycloartanol and cyclohexanol, choline, oleanolic acid. Consumption of this plant gives a cooling effect to the eyes, relieves floating abdomen and liver diseases. It is also an antidote for snake bites and scorpion stings. the dried plant is used as blood purifier and cures skin diseases (Walter, Merish and Tamizhamuthu, 2014).Although other therapeutic properties of $A$. sessilis were reported, studies to evaluate the xanthine oxidase inhibitory effect of A.sessilis is scarce. The aim of this study focuses on the above lacunae, that is xanthine oxidase inhibitory effect of Alternanthera sessilis.

\section{MATERIAL AND METHODS}

2.1 Preparation of A. sessilis extract: Ethanolic extract of A.sessilis was prepared. Dried leaf powder of A.sessilis was extracted using ethanol. This extract was kept for one day and then filtered. The extract thus prepared was dried and used for assessing the xanthine oxidase inhibitory activity.

2.2. In vitro xanthine oxidase inhibitory effect of $A$. sessilis: In vitro xanthine oxidase inhibitory effect of A.sessilis was assessed as per the method of (Nguyen et al., 2004) and (Umamaheswari et al., 2007). Briefly the assay mixture consisted of $1 \mathrm{ml}$ of extract ( 0.1 to $0.5 \mathrm{~g} / \mathrm{ml}) 2.9 \mathrm{ml}$ of phosphate buffer $(\mathrm{pH} 7.5)$ and 0.1 $\mathrm{ml}$ of xanthine oxidase enzyme solution (0.1 unit / $\mathrm{ml}$ in phosphate buffer, $\mathrm{pH}$ 7.5), which was prepared immediately before use. After preincubation at 25degree Celsius for 15 mins, the reaction was initiated by the addition of $2 \mathrm{ml}$ of substrate solution (150M xanthine in the same buffer). The assay mixture was incubated at 25 degree Celsius for 30 minutes. The reaction was then stopped by addition of $1 \mathrm{ml}$ of $1 \mathrm{~N}$ hydrochloric acid and the absorbance was measured at 290nm using UV spectrometer. Allopurinol (0.1 to $0.5 \mathrm{mg} / \mathrm{ml})$, a known inhibitor of xanthine oxidase was used as the positive control. One unit of xanthine oxidase is defined as the amount of enzyme required to produce $1 \mathrm{mmol}$ of uric acid/min at 25 degrees. Xanthine oxidase inhibitory activity was expressed at the percentage inhibition of xanthine oxidase in the above assay system calculated as percentage of inhibition as follows

$$
\% \text { of inhibition }=\mathrm{Ac}-\mathrm{At} / \mathrm{Ac} \times 100
$$

Ac is the absorbance of control reaction and At is the absorbance of test reaction. The assay was done in triplicate for each concentration. Allopurinol (0.1 to 0.5 microgram/ ml) was used as standard.

\section{Phytochemical screening:}

2.3.1. Test for phlobatannins: $1 \mathrm{ml}$ of A.sessilis extract is added to $1 \mathrm{ml}$ of $\mathrm{HCl}$ and boiled. Formation of red colour indicated the presence of phlobatannins 


\subsubsection{Test for carbohydrates}

a. Fehling's test: $1 \mathrm{ml}$ of the extract is added to $3 \mathrm{ml}$ of Fehling's a and b solution and kept in a boiling water bath for 3 mins. The reddish-brown precipitate formation indicates the presence of carbohydrate.

b. Benedict's test: $1 \mathrm{ml}$ of extract is added to $3 \mathrm{ml}$ of Benedict's solution and kept in a boiling water bath for 3 minutes. Red green and brown colour might be seen which indicates the presence of carbohydrates.

2.3.3. Test for flavonoids: $1 \mathrm{ml}$ of extract is added to $1 \mathrm{ml}$ of 3\% liquid ammonia. Yellow coloured solution formed, confirms the presence of flavonoids.

Figure 1: Xanthine oxidase inhibitory activity of A.sessilis leaf extract. Allopurinol used as standard. Each bar represents the mean \pm SEM of 3 independent observations. $P$ value $<0.05$ is considered to be significant.

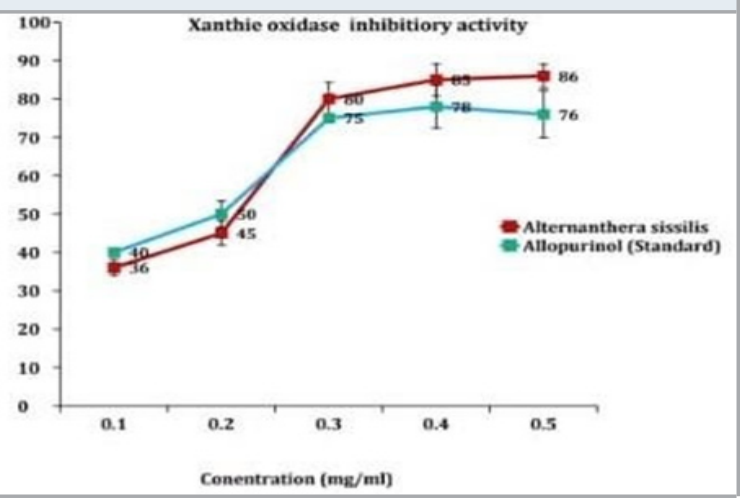

2.3.4. Test for alkaloids: $1 \mathrm{ml}$ of extract is added to $5 \%$ $\mathrm{HCl}$ solution and the formation creamish pale yellow solution is observed which confirms the presence of alkaloids.

2.3.5. Test for terpenoids: $1 \mathrm{ml}$ of extract with addition of $3 \mathrm{ml}$ of chloroform and $2 \mathrm{ml}$ of $5 \%$ conc. Sulphuric acid. This indicates the formation of a red colour solution confirms the presence of terpenoids.

4 Statistical Analysis: The data were subjected to the statistical analysis using one-way analysis of variance (ANOVA) and Duncan's multiple range test to assess the significance of individual variation between the groups. In Duncan's test, the significance was considered at the level of $\mathrm{p}<0.05$.

\section{RESULT AND DISCUSSION}

Xanthine oxidase inhibitory effect of the ethanolic extract of A.sessilis was done at different concentrations (Figure 1). The effect of the extract was compared to that of the standard drug allopurinol. Extract of A.sessilis showed lesser effect than the standard drug at lower concentrations. But as the concentration increases the activity of the extract was found to be better than the standard drug allopurinol (Figure I). Xanthine oxidase is an important biological source of oxygen-derived free radicals which contribute to oxidative damage to living tissues involved in many pathological processes including inflammation, atherosclerosis, cancer, aging and gout (Chiang, Lo and Lu, 1994). The elevation of oxidative stress has been reported in gouty patients (Urano et al., 2002).

Table 1. Phytochemical screening of A.sessilis leaf extract

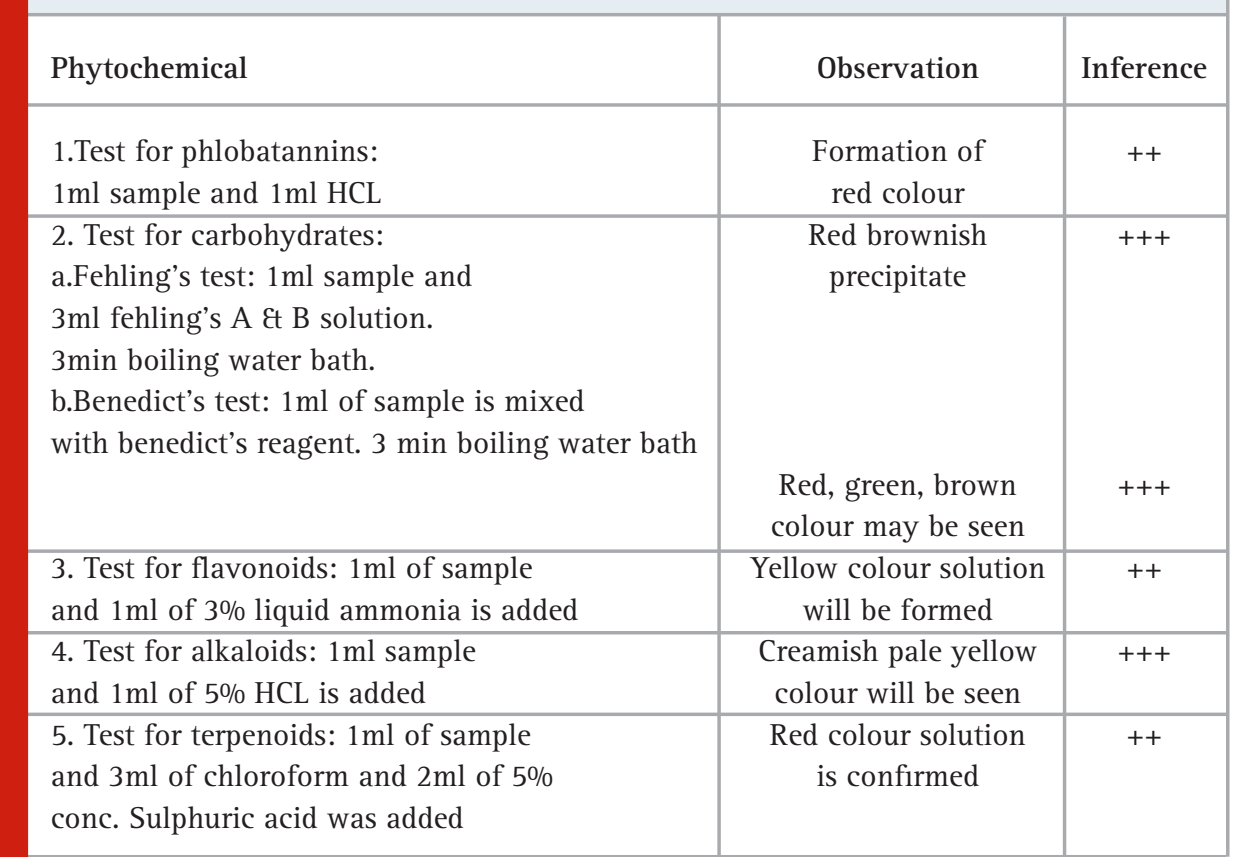


The bioactive compounds having the xanthine oxidase inhibitory effect will help to reduce inflammation and hyperuricemia. Although allopurinol has been successfully used to reduce uric acid level, it is still not the right drug for the treatment of acute gouty arthritis (Dubchak and Falasca, 2010). Allopurinol generates superoxide and can develop undesirable symptoms in persons that are allergic to allopurinol (Mohamed Isa, Ablat and Mohamad, 2018). Since our extract is from natural origin and will not have any side effects, this plant can be used for the development of drug against gout, as it possesses significant inhibition towards xanthine oxidase.

Phyto constituents are the natural bioactive compounds found in plants. Phytochemicals are basically divided into two groups, i.e. primary and secondary constituents; according to their functions in plant metabolism. Primary constituents comprise common sugars, amino acid, proteins and chlorophyll while secondary constituents consist of alkaloids, terpenoid, steroids and flavonoids, so on. (Thilagavathi et al., 2015). The presence of phytochemicals shows the bioactive activities in the plants and has antioxidant activities. Flavonoids act as health components. Alkaloids are present and they involve medicinal uses (Aiyegoro and Okoh, 2010). Our study showed that A.sessilis extract leaf extract is abundant in carbohydrates and alkaloids moderately rich in phlobatannins, flavonoids and terpenoids (Table 1). All biological activities of herbal medicine are attributed to the presence of phytochemicals in it. The presence of these phytochemicals might be also the underlying reason for the inhibition of xanthine oxidase activity.

\section{CONCLUSION}

To conclude, the present study revealed that $A$. sessilis leaf extract is effective in inhibiting the xanthine oxidase enzyme activity in vitro and is rich in phytochemical components. The phytochemical constituents in the extract might have contributed to the beneficial effect of this extract.

\section{ACKNOWLEDGEMENTS}

This research was done under the supervision of the Department of Research of Saveetha Dental College and Hospitals. We sincerely show gratitude to the corresponding guides who provided insight and expertise that greatly assisted the research.

\section{Conflicts of Interest: None declared}

\section{REFERENCES}

Aiyegoro, 0. A. and Okoh, A. I. (2010) 'Preliminary phytochemical screening and in vitro antioxidant activities of the aqueous extract of Helichrysum longifolium DC', BMC complementary and alternative medicine. Springer, 10, p. 21.

Borges, F., Fernandes, E. and Roleira, F. (2002) 'Progress towards the discovery of xanthine oxidase inhibitors',
Current medicinal chemistry. ingentaconnect.com, 9(2), pp. 195-217.

Busso, N. and So, A. (2010) 'Mechanisms of inflammation in gout', Arthritis research \&t therapy. Springer, 12(2), p. 206.

Chiang, H. C., Lo, Y. J. and Lu, F. J. (1994) 'Xanthine oxidase inhibitors from the leaves of Alsophila spinulosa (Hook) Tryon', Journal of enzyme inhibition. Taylor \& Francis, 8(1), pp. 61-71.

Dubchak, N. and Falasca, G. F. (2010) 'New and improved strategies for the treatment of gout', International journal of nephrology and renovascular disease. ncbi. nlm.nih.gov, 3, pp. 145-166.

Elion, G. B., Kovensky, A. and Hitchings, G. H. (1966) 'Metabolic studies of allopurinol, an inhibitor of xanthine oxidase', Biochemical pharmacology. Elsevier, 15(7), pp. 863-880.

Ferraz Filha, Z. S. et al. (2006) 'Xanthine oxidase inhibitory activity of Lychnophora species from Brazil (“Arnica”)', Journal of ethnopharmacology. agris.fao. org, 107 issue 1. doi: 10.1016/j.jep.2006.02.011.

Grubben, G. J. H. and Denton, O. A. (2004) 'Plant Resources of Tropical Africa 2. Vegetables. PROTA Foundation, Wageningen, Netherlands', backhuys Publishers, Leiden, Netherlands/CTA, Wgeningen Netherlands. Http://www/hort. purdue/edu/newcrop. duke_energy/moringa, htm. Accessed on, 4(05), p. 2008.

Hossain, A. I. et al. (2014) 'A preliminary evaluation of antihyperglycemic and analgesic activity of Alternanthera sessilis aerial parts', BMC complementary and alternative medicine. Springer, 14, p. 169.

Kumar, A. et al. (2014) 'Antimicrobial activity study of ethanolic extract of Alternanthera sessilis linn. aerial parts', Journal of Applied Pharmaceutical Research. japtronline.com, 2(3), pp. 01-04.

Mohamed Isa, S. S. P., Ablat, A. and Mohamad, J. (2018) 'The Antioxidant and Xanthine Oxidase Inhibitory Activity of Plumeria rubra Flowers', Molecules . mdpi. com, 23(2). doi: 10.3390/molecules23020400.

Morgan, E. J. (1926) 'The Distribution of Xanthine Oxidase I', Biochemical Journal. portlandpress.com, 20(6), pp. 1282-1291.

Nguyen, M. T. T. et al. (2004) 'Xanthine oxidase inhibitory activity of Vietnamese medicinal plants', Biological \& pharmaceutical bulletin. jstage.jst.go.jp, 27(9), pp. 1414-1421.

Roddy, E. and Doherty, M. (2010) 'Epidemiology of gout', Arthritis research \& therapy. Springer, 12(6), p. 223.

Taxon, O. F., Red, I. and List, R. (2015) 'Appendix 5. Wetland Dependent Plants of the Arabian Peninsula', The Status and Distribution of Freshwater Biodiversity in the Arabian Peninsula. by: IUCN, Gland, Switzerland, 
Cambridge, UK, and Arlington, USA, p. 99.

Thilagavathi, T. et al. (2015) 'Preliminary Phytochemical screening of different solvent mediated medicinal plant extracts evaluated', Int. Res. J. Pharm, 6(4), pp. 246-248.

Umamaheswari, M. et al. (2007) 'Xanthine oxidase inhibitory activity of some Indian medical plants', Journal of ethnopharmacology. Elsevier, 109(3), pp. 547-551.
Urano, W. et al. (2002) 'The inflammatory process in the mechanism of decreased serum uric acid concentrations during acute gouty arthritis', The Journal of rheumatology. jrheum.org, 29(9), pp. 1950-1953.

Walter, T. M., Merish, S. and Tamizhamuthu, M. (2014) 'Review of Alternanthera sessilis with reference to traditional Siddha medicine', International Journal of Pharmacognosy and Phytochemical Research. academia. edu, 6(2), pp. 249-254. 